\title{
Synthesis of Bis-Terpyridine-Based Metallopolymers and the Thermoelectric Properties of Their Single Walled Carbon Nanotube Composites
}

\author{
Jiahua Li ${ }^{1} \mathbb{D}$, Zeling Guo ${ }^{1}$, Linli Xu ${ }^{1,2} \mathbb{D}$ and Wai-Yeung Wong ${ }^{1,2, *(\mathbb{D}}$ \\ 1 Department of Applied Biology and Chemical Technology and Research Institute for Smart Energy, \\ The Hong Kong Polytechnic University, Hung Hom, Kowloon, Hong Kong, China; \\ koopa.1.li@connect.polyu.hk (J.L.); zeling.guo@connect.polyu.hk (Z.G.); linli.xu@polyu.edu.hk (L.X.) \\ 2 The Hong Kong Polytechnic University Shenzhen Research Institute, Shenzhen 518057, China \\ * Correspondence: wai-yeung.wong@polyu.edu.hk
}

check for updates

Citation: Li, J.; Guo, Z.; Xu, L.; Wong, W.-Y. Synthesis of Bis-

Terpyridine-Based Metallopolymers and the Thermoelectric Properties of Their Single Walled Carbon Nanotube Composites. Molecules 2021, 26, 2560. https://doi.org/10.3390/

molecules 26092560

Academic Editors: Marco Anni and M.-H. Whangbo

Received: 4 March 2021

Accepted: 22 April 2021

Published: 28 April 2021

Publisher's Note: MDPI stays neutral with regard to jurisdictional claims in published maps and institutional affiliations.

Copyright: (c) 2021 by the authors. Licensee MDPI, Basel, Switzerland. This article is an open access article distributed under the terms and conditions of the Creative Commons Attribution (CC BY) license (https:/ / creativecommons.org/licenses/by/ $4.0 /)$.

\begin{abstract}
Although the organic and the conventional inorganic thermoelectric (TE) materials have been extensively developed in recent years, the number of cases involving conducting metallopolymers is still quite limited. In view of the versatile coordination capability of the terpyridine fraction and the electron-rich nature of the 3,4-ethylenedioxythiophene moiety, a bis-terpyridine-featured ligand was designed, and a series of metallopolymers were then synthesized. Upon the addition of single-walled carbon nanotube (SWCNT), the TE properties of the resulting metallopolymer-SWCNT composite films were investigated. It was found that metal centres played an important role in affecting the morphology of the thin films, which was a key factor that determined the TE performances of the composites. Additionally, the energy levels of the metallopolymers were feasibly tuned by selecting different metal centres. With the combined effects of a uniform and condensed surface and an optimized band structure, the highest power factor was achieved by the $\mathrm{Cu}$ (II)-containing metallopolymer-SWCNT composite at the doping ratio of $75 \%$, which reached $38.3 \mu \mathrm{W} \cdot \mathrm{m}^{-1} \cdot \mathrm{K}^{-2}$.
\end{abstract}

Keywords: thermoelectric; metallopolymer; terpyridine; composite

\section{Introduction}

As a green approach to convert heat into electrical energy, thermoelectric (TE) materials are showing their promising prospect in both macro-scaled and mini-scaled applications, such as power generation, health monitors, etc. [1,2], and thus have received tremendous attention. The TE performance of a material is assessed by its figure-of-merit $(Z T): Z T=S^{2} \sigma T / \kappa$, where $S$ is the Seebeck coefficient $\left(\mathrm{V} \cdot \mathrm{K}^{-1}\right), \sigma$ is the electrical conductivity $\left(\mathrm{S} \cdot \mathrm{m}^{-1}\right), T$ is the absolute temperature $(\mathrm{K})$, and $\kappa$ is the thermal conductivity $\left(\mathrm{W} \cdot \mathrm{m}^{-1} \cdot \mathrm{K}^{-1}\right)[2,3]$. Apparently, materials exhibiting high electrical conductivity, high Seebeck coefficient but low thermal conductivity are expected. In this respect, conventional inorganic materials do a great job as they are always demonstrated to show high ZT values exceeding 1.0. For example, via the hot pressing technique, nanocrystalline BiSbTe bulk materials were synthesized from its nanopowders, achieving a peak ZT of 1.4 at $100{ }^{\circ} \mathrm{C}$ [4]. By controlling the doping ratio of iodine, the n-type semiconductor $\mathrm{PbTe}_{1-x} \mathrm{I}_{x}$ gave the ZT value up to 1.4 from $700 \mathrm{~K}$ to $800 \mathrm{~K}$ [5]. In 2020, Zhu et al. developed a bismuth antimony chalcogenide material with the highest $Z T$ value reaching ca. 1.4 within a temperature range from $300 \mathrm{~K}$ to $575 \mathrm{~K}$ [6].

Despite the satisfactory energy conversion efficiency, these inorganic materials bear inevitable shortcomings, including the use of heavy metals and rare elements, their hard and fragile characters, and high performances only at high temperature [7-9]. In contrast, by virtue of good flexibility, light weight, diverse chemical structures, and the ease of processing, a number of organic TE materials have been synthesized and studied. In 
light of the extremely low thermal conductivity (generally below $1 \mathrm{~W} \cdot \mathrm{m}^{-1} \cdot \mathrm{K}^{-1}$ ) [10], another parameter-power factor $(P F)$ - is useful to characterize the TE performance of the organic materials as: $P F=S^{2} \sigma[7,9,10]$. As the most successful instance, poly $(3,4-$ ethylenedioxythiophene):poly(styrenensulfonate) (PEDOT:PSS) has been extensively studied for years, not only due to its high TE performance (sometimes comparable to the inorganics), but it also possesses some attractive features including the realised processibility in aqueous media and high thermal stability [6,11]. By adjusting the stacking structure of PEDOT:PSS, the prepared thin film gave a high $P F$ up to $330.597 \mu \mathrm{W} \cdot \mathrm{m}^{-1}$, and a device was made to recycle the heat in the form of solar energy [12]. Besides, some electron-rich conducting polymers including polypyrroles [13-16], polythiophenes, and their composites $[17,18]$ also exhibited their potential in TE applications.

Emerging as a new class of TE materials, metallopolymer-based TE materials bring the advantages of metallation to pure organic polymers [9]. The involvement of appropriate transition metal ions could increase the probability to provide active species during the electrical conducting process [19-21], tune the energy levels through d- $\pi$ conjugation feasibly $[19,22]$, generate various molecular geometries according to the coordinating properties of the metal centres and lower the thermal conductivity [9]. In this regard, Zhu et al. successfully developed a series of 1,1,2,2-ethenetetrathiolatebased metallopolymers [poly $(\mathrm{M}(\mathrm{ett})]$ with tunable TE performances when different metal centres or processing methods were adopted [23-25]. For example, poly[ $\mathrm{Na}_{x}(\mathrm{Ni}$-ett)] and poly $\left[\mathrm{K}_{x}(\mathrm{Ni}\right.$-ett) $]$ were demonstrated to be n-type semiconductors with their roomtemperature (RT) $P F$ of around $26 \mu \mathrm{W} \cdot \mathrm{m}^{-1} \cdot \mathrm{K}^{-2}$, but poly[Cu $(\mathrm{Cu}$-ett)] was a p-type TE material which produced the RT PF of $38.6 \mu \mathrm{W} \cdot \mathrm{m}^{-1} \cdot \mathrm{K}^{-2}$ [23]. Other representative cases mainly included 2,3,6,7,10,11-hexaiminotriphenylene- $[26,27]$ and porphyrin-based 2D framework materials $[28,29]$ and metalated poly(Schiff base)s [30,31]. However, the number of metallopolymer-derived TE materials is still quite limited.

In light of the versatile coordination capability [32-36], the terpyridine moiety always appears as a popular fragment in coordination chemistry, and its related materials were found to exhibit interesting properties in a wide range of applications. For example, in 2016, Liang et al. synthesized a series of bis(terpyridine)-based Fe(II) complexes which displayed rapid and reversible electrochromic behaviour between blue and pale yellow upon repeated redox process [37]. By employing a hexylthiophene-modified terpyridine as the ligand and $\mathrm{Ru}(\mathrm{II})$ as the metal centre, two ruthenium-containing sensitizers for solar cells have been developed and improved molar absorption coefficients were observed [38]. Additionally, a metal-organic framework based on Eu(III) and terpyridine was proved to be a highly selective and sensitive probe for $\mathrm{Fe}^{3+}$ in aqueous solution and even in biological systems [39]. Moreover, Elgrishi found that the reduction of proton and $\mathrm{CO}_{2}$ could be feasibly realised under the catalysis of several cobalt-terpyridine coordination compounds [40]. However, the application of terpyridine-based materials towards TEs is still rarely seen.

In this work, a bis(terpyridine)-based new ligand was designed. The EDOT fragment was selected as the bridge to link the two terminal terpyridine chelating sites, due to its electron-rich property as well as the potential capability to enhance the TE performance [41]. Through the coordination with various transition metal ions $\left(\mathrm{Co}^{2+}, \mathrm{Ni}^{2+}\right.$ and $\left.\mathrm{Cu}^{2+}\right)$, a series of terpyridine-based metallopolymers were prepared (Figure 1). Then, by blending with single-walled carbon nanotubes (SWCNTs), the TE properties of the resulting composites were measured at different doping ratios $\left(f_{\mathrm{C}}, f_{\mathrm{C}}=m_{\mathrm{SWCNT}} / m_{\text {composite }}\right)$. The factors that affected the TE performance are discussed in detail from the perspectives of the morphology evolution and the role played by metal centres were highlighted. It is the first time that the TE performance of the terpyridine-based metallopolymer-SWCNT composite materials was assessed systematically. 

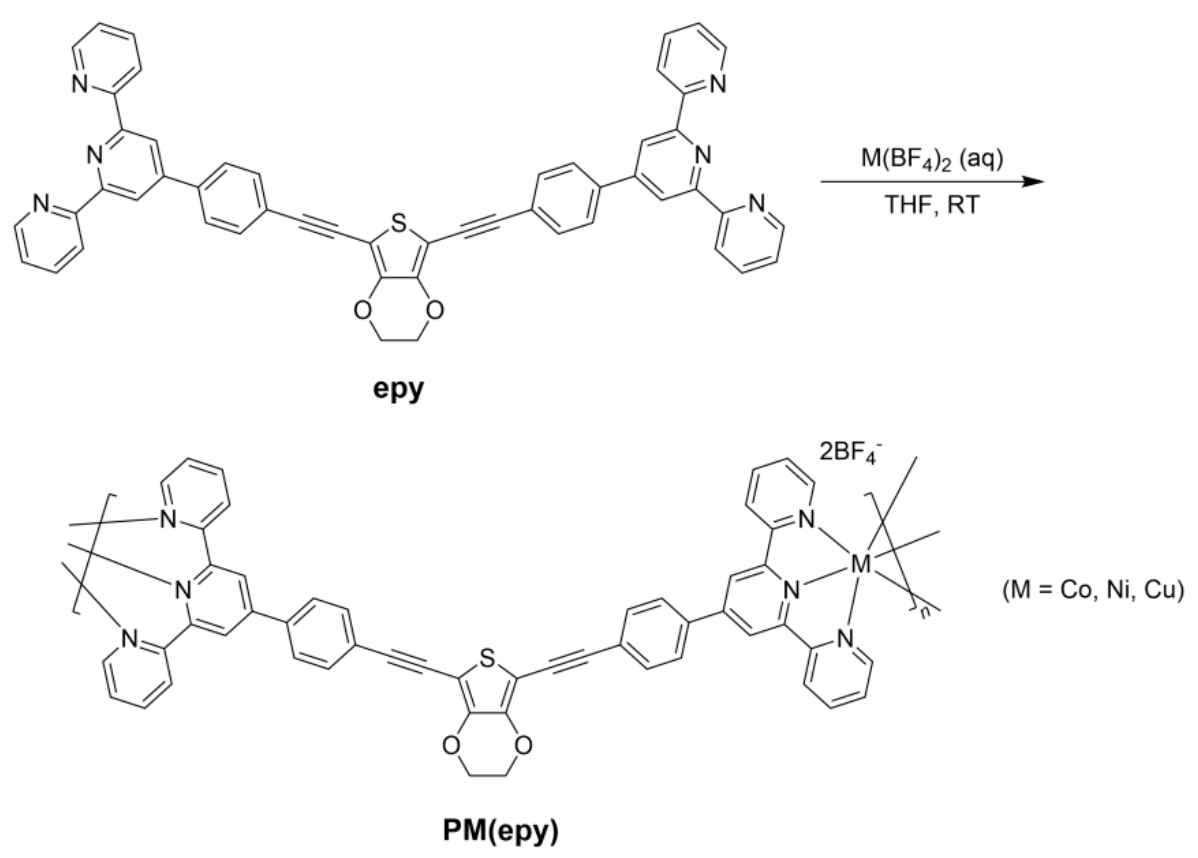

Figure 1. Synthetic route of PM(epy).

2. Materials and Methods

2.1. Materials

$\mathrm{Co}\left(\mathrm{BF}_{4}\right)_{2} \cdot 6 \mathrm{H}_{2} \mathrm{O}$ and $\mathrm{Cu}\left(\mathrm{BF}_{4}\right)_{2} \cdot 6 \mathrm{H}_{2} \mathrm{O}$ were purchased from Energy Chemical, and $\mathrm{Ni}\left(\mathrm{BF}_{4}\right)_{2} \cdot 6 \mathrm{H}_{2} \mathrm{O}$ was purchased from Alfa Aesar. SWCNTs (purity $>95 \%$ ), with diameters of 1-2 $\mathrm{nm}$ and lengths of 5-30 $\mu \mathrm{m}$, were purchased from XFNANO. 1,2-Dichloroethane was purchased from TCI, and other organic solvents were purchased from Alfa Aesar. Flat glass sheets with a dimension of $15 \mathrm{~mm} \times 15 \mathrm{~mm} \times 1 \mathrm{~mm}$ (length $\times$ width $\times$ height) were cleaned and used as substrates for the film deposition. As a typical cleaning procedure, the glass sheets were fully immersed and sonicated in the aqueous solutions of $5 \%$ hydrochloric acid and 5\% sodium carbonate successively, washed with deionized water before and after each sonication, and finally rinsed with absolute ethanol thoroughly before drying in vacuo.

\subsection{Synthesis}

\subsubsection{Preparation of the Metallopolymer PM(epy)}

The detailed synthetic route is shown in Figure S1. As a general procedure, $19 \mathrm{mg}$ epy $(24 \mu \mathrm{mol})$ was dissolved in $10 \mathrm{~mL}$ THF under nitrogen. With vigorous stirring, a solution of $24 \mu \mathrm{mol} \mathrm{M}\left(\mathrm{BF}_{4}\right)_{2}$ in a mixed solvent of $0.5 \mathrm{~mL}$ deionized water and $2 \mathrm{~mL} \mathrm{MeOH}$ was added into the ligand solution in a dropwise manner. The reaction was maintained at RT for 1 day, after which the precipitate was collected by filtration, washed thoroughly with deionized water and THF, and dried in a vacuum oven. Pure PCo(epy), PNi(epy), and PCu(epy) were furnished as a red powder, a dark yellow powder, and a brown powder, respectively.

\subsubsection{Preparation of PM(epy)-SWCNT Composite Films}

In a round-bottomed flask, $50 \mathrm{mg}$ SWCNT and $50 \mathrm{~mL}$ 1,2-dichloroethane were mixed. Then, the flask was immersed in an ice bath at $0{ }^{\circ} \mathrm{C}$ and the mixture was dispersed with an ultrasonic homogenizer at a power of $95 \mathrm{~W}$ for $1.5 \mathrm{~h}$. To a glass vial containing a specific amount of the metallopolymer powder, $1.0 \mathrm{~mL}$ of the formed SWCNT dispersion was added. Then, the vials were sealed and sonicated at $0{ }^{\circ} \mathrm{C}$ for $2 \mathrm{~h}$. After that, gel-like mixtures were formed and dropped onto clean glass substrates. Qualified thin composite films were obtained after solvent evaporation and their thickness was measured before the measurements of the TE properties. 


\subsection{Characterization}

The nuclear magnetic resonance (NMR) spectra were acquired on a Varian VNMRS 400 spectrometer or a Bruker AVANCE III 400 spectrometer. ${ }^{1} \mathrm{H}$ NMR spectra were quoted relative to the internal reference tetramethylsilane (TMS, $\delta=0.00 \mathrm{ppm}$ ). For ${ }^{13} \mathrm{C}$ NMR acquisitions, the spectra were referenced to the recommended values [42] of the deuterated solvent signals: $\delta\left(d_{6}\right.$-acetone $)=29.84 \mathrm{ppm}, \delta\left(\mathrm{CDCl}_{3}\right)=77.16 \mathrm{ppm}$, and $\delta\left(d_{8}-\mathrm{THF}\right)=25.31 \mathrm{ppm}$. Matrix-assisted laser desorption/ ionization-time of flight (MALDI-TOF) mass spectra were acquired on a Bruker UltrafleXtreme MALDI-TOF mass spectrometer with $\alpha$-cyano-4hydroxycinnamic acid or 2,5-dihydroxybenzoic acid employed as the matrix. Samples for Fourier-transform infrared (FTIR) spectroscopy were prepared by using the KBr pellets and the spectra were measured on an Agilent Cary 670 spectrometer. Raman spectra were collected on a Renishaw Micro-Raman microscope, under the irradiation of a laser at $785 \mathrm{~nm}$. Scanning electron microscopic (SEM) images were captured on a JEOL JSM-6490 electron microscope. Transmission electron microscopic (TEM) images were obtained on a JEOL JEM-2100F model. Elemental analysis was tested on a Vario EL Cube elemental analyser. UV-Vis reflection spectra of powdered samples were collected on a Varian Cary 4000 spectrophotometer with the integrating sphere accessories. The UV-Vis-NIR absorption spectrum was measured on a Shimadzu UV-3600 Plus spectrometer. The X-ray photoelectron spectra (XPS) were acquired on a Thermo Scientific Nexsa system. Each survey spectrum was accumulated for 5 times and each high-resolution spectrum was acquired with 20 scans. The thickness of the thin films was measured on a Bruker DektakXT Surface optical profiler equipped with a diamond-tipped stylus showing a radius of $2.5 \mu \mathrm{m}$.

The TE properties of the thin films were tested on a JouleYacht MRS-3RT TE Testing System at RT. The glass substrate with the thin film was fixed in the sample chamber where light was avoided. The four-point method was applied to measure the electrical conductivity. For the tests of Seebeck coefficient, the temperature gradient was generated between two thermocouples where one maintained the temperature of the cold terminal at around RT and the other one heated the films up gradually. The highest temperature of the hot end was confined within $60^{\circ} \mathrm{C}$ and the entire heating process took ca. $60 \mathrm{~s}$. The whole course was controlled automatically by the system and the data were recorded in real time. Upon each completion of the Seebeck coefficient measurement, the heating process stopped immediately and the thin film was allowed to cool to RT naturally.

\section{Results and Discussion}

\subsection{Chemical Structure Determination}

Due to the highly conjugated and rigid molecular structures, all these metallopolymers were insoluble in common organic solvents. Consequently, their nuclear magnetic resonance spectra were not obtained. As a workaround, FTIR spectroscopy was used to determine the chemical structures of the products. As displayed in Figure 2, the absorption bands within the spectral region from $3200 \mathrm{~cm}^{-1}$ to $2800 \mathrm{~cm}^{-1}$ were assigned to the stretching vibration of C-H bond [43]. The peaks shown at $2186 \mathrm{~cm}^{-1}$ depict the presence of the internal $\mathrm{C} \equiv \mathrm{C}$ bond [43]. After the metal coordination, the absorption bands at around $1078 \mathrm{~cm}^{-1}$ were broadened, probably due to the combination of the signals from B-F bonds [44]. Particularly, the absorption peak corresponding to the $\mathrm{C}=\mathrm{N}$ stretching vibration of the pyridine ring [34] from epy at $1566 \mathrm{~cm}^{-1}$ shifted to the long wavelength region, which implied the successful coordination of the metal ions. 


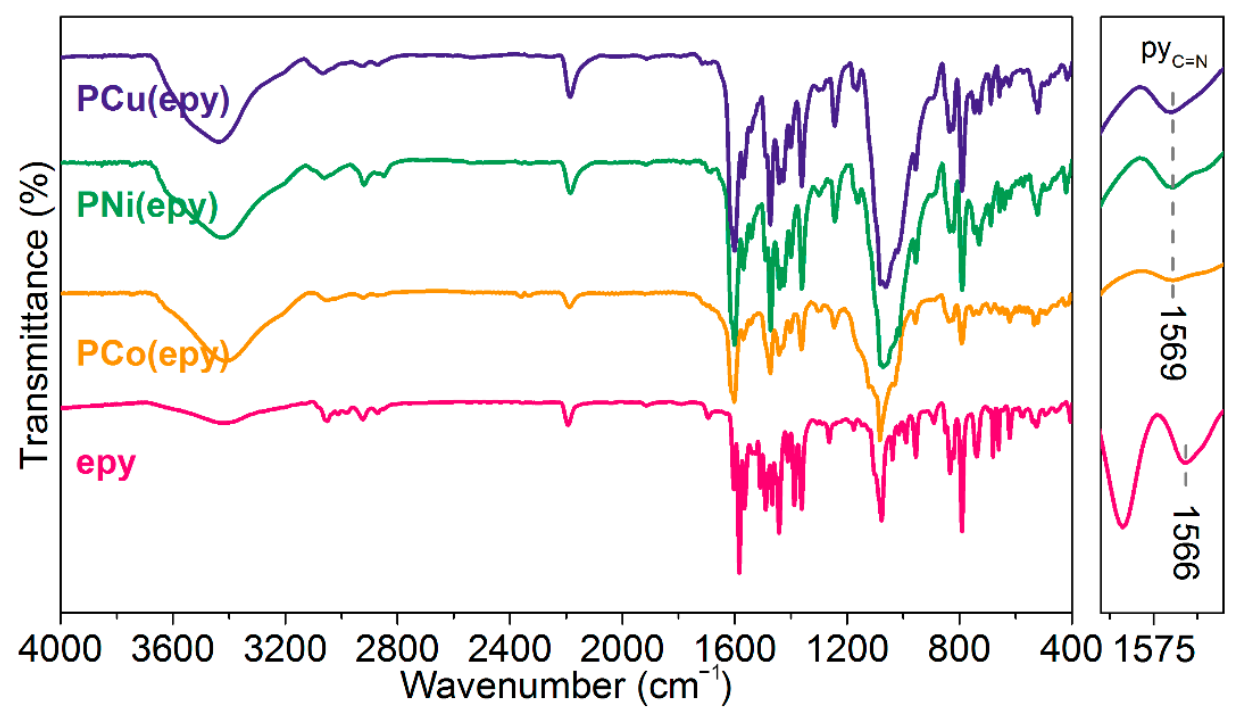

Figure 2. FTIR spectra of PM(epy). Expansion (right): the spectral region involving the absorption of $\mathrm{C}=\mathrm{N}$ bond from the pyridine ring.

\subsection{Electrochemical Properties}

The electrochemical properties of PM(epy) were investigated by cyclic voltammetry (CV). As shown in Figure 3, all metallopolymers exhibited both oxidative and reductive waves, implying their capabilities to convey electrons and holes [45]. At $0.45 \mathrm{~V}$, an irreversible oxidation of the organic backbone was detected for all metallopolymers, from which the highest occupied molecular orbital (HOMO) or singly occupied molecular orbital (SOMO) energy values were calculated and listed in Table 1. It can be seen that the incorporation of these metal ions hardly affected the positions of the HOMO or SOMO levels. PNi(epy) exhibited an additional wave at ca. $0.97 \mathrm{~V}$, which may be ascribed to the oxidative process from $\mathrm{Ni}(\mathrm{II})$ to $\mathrm{Ni}(\mathrm{III})$ [20]. At the reduction region, a characteristic redox-reversible process was detected at $-1.16 \mathrm{~V}$ from PCo(epy), which revealed the electrochemical conversion between $\mathrm{Co}(\mathrm{II})$ and $\mathrm{Co}(\mathrm{I})$ [46-48]. By comparison, the electrochemical process occurring on the metal centre of $\mathbf{P C u}($ epy) was not found, which implied the redox-inactive property of $\mathrm{Cu}(\mathrm{II})[20]$.

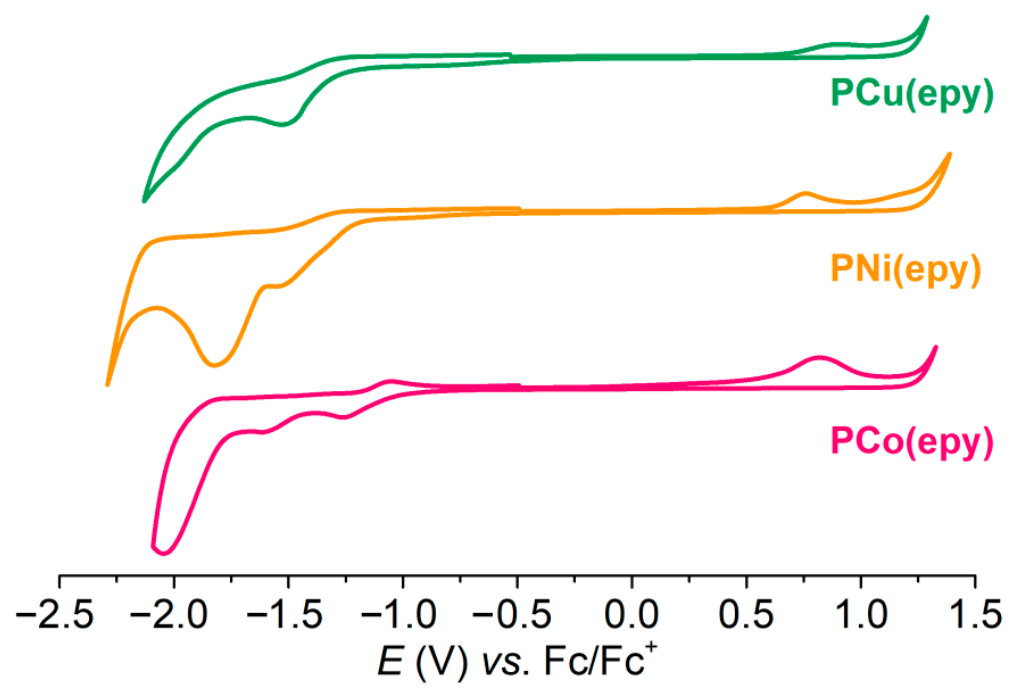

Figure 3. Cyclic voltammograms of PCo(epy), PNi(epy), and $\mathbf{P C u}\left(\right.$ epy) in degassed $\mathrm{CH}_{2} \mathrm{Cl}_{2}$. 
Table 1. The HOMO or SOMO energies of PM(epy).

\begin{tabular}{cc}
\hline Metallopolymers & HOMO or SOMO (eV) \\
\hline PCo(epy) & -5.00 \\
PNi(epy) & -5.01 \\
PCu(epy) & -5.06 \\
\hline
\end{tabular}

\subsection{Morphology Studies}

The morphology of the prepared composite thin films was studied under an SEM. As revealed in Figure 4, the morphology change of the thin films heavily depended on the SWCNT content. At $f_{\mathrm{C}}=15 \%$, serious macro-phase separation was observed. SWCNTs formed condensed layered structures with large metallopolymer aggregates sitting atop or sandwiched between adjacent layers. A closer observation found that the aggregated PNi(epy) particles are of smaller size than other two analogues (Figure 4d), suggesting an improved contact area with SWCNTs. PCu(epy) formed a layer-by-layer structure with smooth surface (Figure $4 \mathrm{~g}$ ), which was in favour of establishing strong interfacial interactions with the SWCNTs. At the medium doping level $\left(f_{\mathrm{C}}=60 \%\right)$, much better dispersed composites were developed, except for PCo(epy)-SWCNT where the aggregation of the metallopolymer was not effectively alleviated (Figure $4 \mathrm{~b}$ ). By contrast, the PCu(epy)-SWCNT composite was highlighted by its uniform morphology (Figure 4h). All metallopolymer particles were perfectly dispersed and coated on the SWCNT network evenly. With the CNT content increased up to $90 \%$, a homogeneous surface was evolved. A condensed and inter-connected CNT network was observed and the inter-layered interaction was significantly enhanced with only a few PCo(epy) and PNi(epy) particles appeared, which provided an efficient charge carrier transporting system.
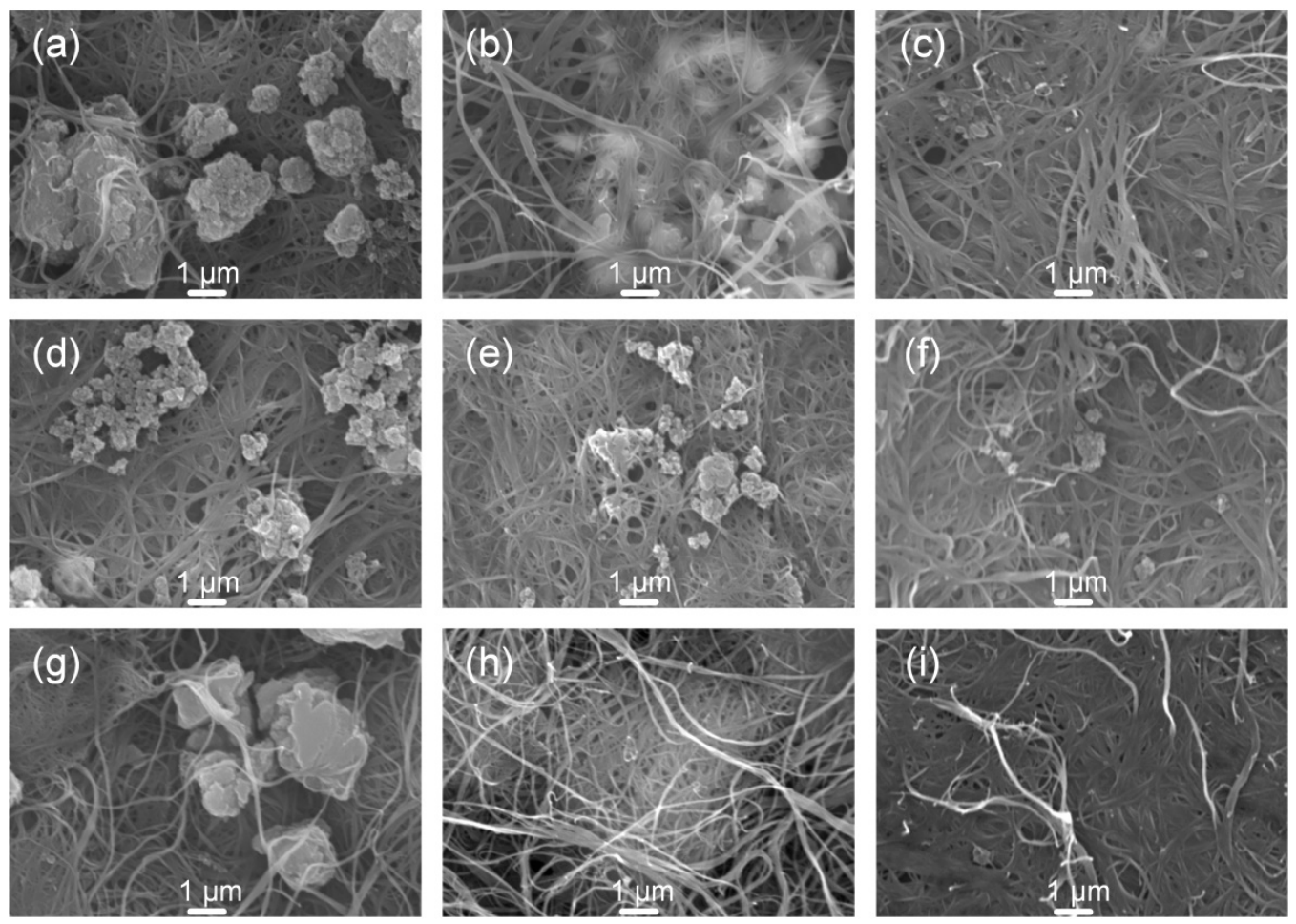

Figure 4. SEM images of the (a-c) PCo(epy)-SWCNT, (d-f) PNi(epy)-SWCNT, and (g-i) PCu(epy)SWCNT composites films with the doping ratio $\left(f_{\mathrm{C}}\right)$ of $15 \%$ (left column), 60\% (middle column), and 90\% (right column). 


\subsection{Raman Spectral Analysis of the PM(epy)-SWCNT Composites}

The gradual evolution of the morphology possibly implied the effective establishment of the interactions between the metallopolymers and SWCNTs. Here, Raman spectra were acquired for verification. As shown in Figure 5, a series of characteristic absorption peaks were detected from the Raman spectrum of the pure SWCNT thin film, including a radial breathing mode (RBM) at $161 \mathrm{~cm}^{-1}$, a D-band from $\mathrm{sp}^{3}$-hybridized carbon atoms at $1306 \mathrm{~cm}^{-1}$, a G-band from sp ${ }^{2}$-hybridized carbon atoms (involving a G. band at $1571 \mathrm{~cm}^{-1}$ and a $\mathrm{G}_{+}$band at $1592 \mathrm{~cm}^{-1}$ ), and a 2D band at $2591 \mathrm{~cm}^{-1}$ [49]. After doping with PM(epy), a slight spectral shift of the $\mathrm{G}_{+}$band was found, especially for PCu(epy)-SWCNT composite whose peak shifted to the long wavelength region the most significantly, which may benefit from the increased contact area. This phenomenon revealed the presence of the interfacial interactions between the metallopolymers and the SWCNTs. Besides, for the composites, the emergence of the new peak at $2192 \mathrm{~cm}^{-1}$ corresponded to the stretching vibration of the $\mathrm{C} \equiv \mathrm{C}$ bond. The presence of additional peaks from PCu(epy) may imply that the energy gap of the metallopolymer matched well with the energy of the incident laser.

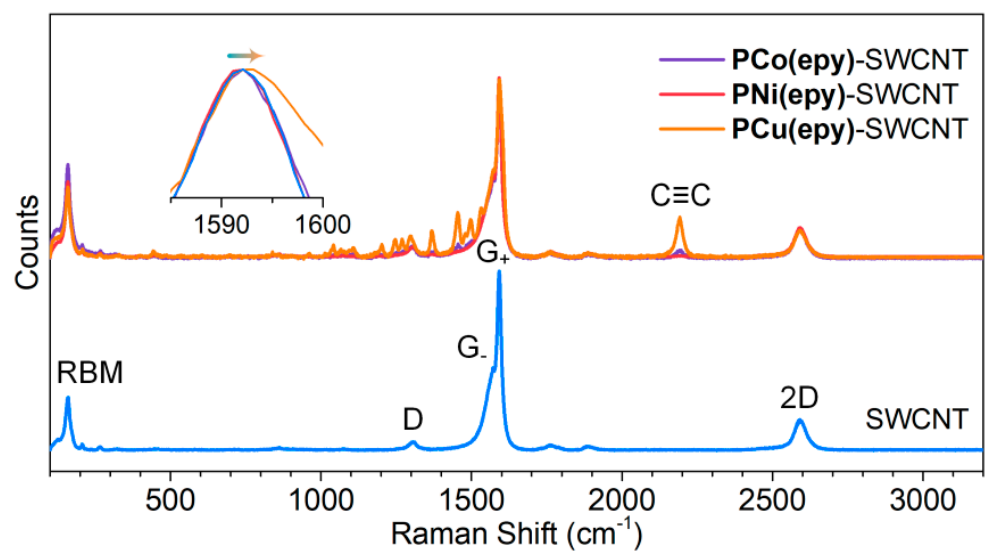

Figure 5. Raman spectra of pure SWCNTs and the PM(epy)-SWCNT composites at $f_{C}=60 \%$.

\subsection{TE Performances}

The electrical conductivities and the Seebeck coefficients of the prepared composites were assessed on a JouleYacht MRS-3RT TE testing system at RT. From Figure 6a, the increasing amount of SWCNT helped to boost the electrical conductivity of the composite remarkably. At $f_{\mathrm{C}}=15 \%$, PNi(epy)-SWCNT and PCu(epy)-SWCNT showed almost the same conductivity, which was $60 \%$ higher than that of the PCo(epy)-SWCNT composite. As for PNi(epy), the CV curves displayed that the oxidation wave of the metal centre was quite close to that of the organic backbone, which may imply a redox-matched scenario. Judging from the molecular structures, all these metallopolymers are Wolf type III conducting polymers where metal centres appear in the polymer main chain and act as linkers [50]. In a typical conducting process, the oxidized organic backbone was doped and became a highly conductive bridge or a hopping station between any adjacent two metal centres at different oxidation states $\left(\mathrm{Ni}^{2+} / \mathrm{Ni}^{3+}\right)$. The resulting inter-chain interactions and intra-chain charge transfer in superexchange (Figure 7a) and charge hopping (Figure $7 \mathrm{~b}$ ) fashions together account for the high electrical conductivity $[19,20]$. In the case of PCu(epy)-SWCNT, although $\mathrm{Cu}^{2+}$ was considered redox-inactive and the composite should have suffered from low conductivity, a high conductivity was detected unexpectedly. The possible reasons could be due to the flat surfaces of $\mathbf{P C u}(\mathbf{e p y})$ particles, the resulting stronger interactions with the SWCNT networks and the paramagnetic property of $\mathrm{Cu}^{2+}$ [51]. By contrast, large aggregates of PCo(epy) not only enlarged the distance between adjacent SWCNT networks, but also decreased the contact area. The increment of the doping ratio brought about a significant enhancement on the electrical conductivities of all composites, which benefited from the gradual formation of a uniform composite surface and increased 
charge carrier concentration. Notably, PCu(epy)-SWCNT always kept the highest value at all doping ratios, with the top value reaching $4.41 \times 10^{4} \mathrm{~S} \cdot \mathrm{m}^{-1}$.
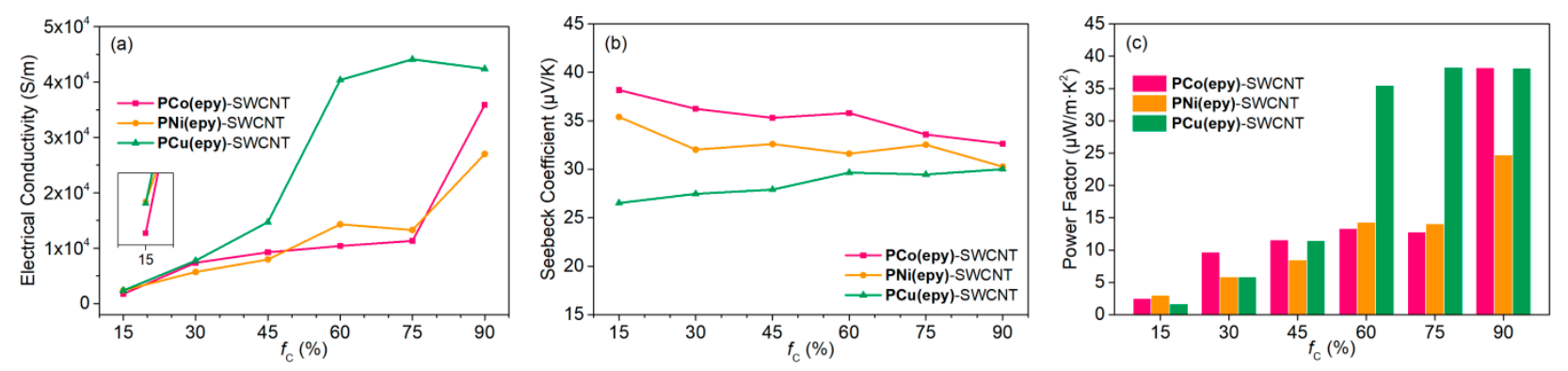

Figure 6. (a) Electrical conductivity, (b) Seebeck coefficient, and (c) $P F$ of the PM(epy)-SWCNT composites at various $f_{\mathrm{C}}$.

(a)

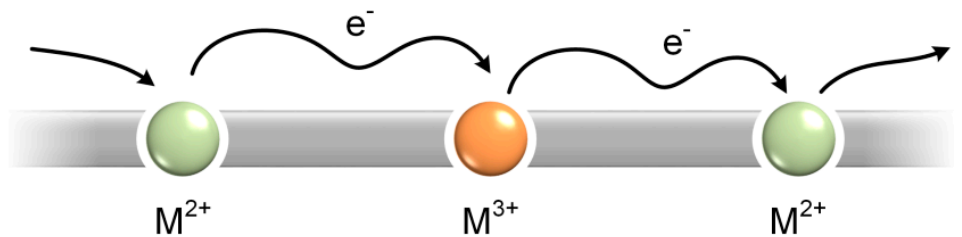

(b)

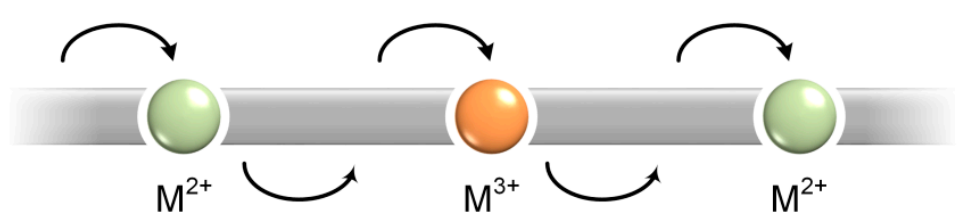

Figure 7. The charge carrier transmission in Wolf type III conducting metallopolymers via (a) superexchange or (b) hopping behaviours.

The dependence of Seebeck coefficient on $f_{\mathrm{C}}$ was shown in Figure $6 \mathrm{~b}$. As expected, all samples gave positive $S$ values, suggesting that holes were the main charge carriers and these composites were p-type conductors. When more SWCNT were introduced, the Seebeck coefficients of PCo(epy)-SWCNT and PNi(epy)-SWCNT dropped, which was caused by the inversed relationship between electrical conductivity and Seebeck coefficient [3]. However, the $S$ value of the PCu(epy)-SWCNT composites climbed up slightly. Such an interesting phenomenon probably stemmed from the energy filtering effect at the PCu(epy)-SWCNT interfaces. At the crystallite boundaries, such an effect filtered off most low-energy charge carriers and only those with high energy were allowed to transmit [52-54]. In view of the better developed interfacial interactions, the energy filtering effect played a leading role in determining the Seebeck coefficient, and therefore gradually elevated $S$ values were recorded at high $f_{\mathrm{C}}$.

The PFs of the composite thin films were shown in Figure $6 c$, which exhibited a similar variation trend to the electrical conductivity. The highest $P F$ of $38.29 \mu \mathrm{W} \cdot \mathrm{m}^{-1} \cdot \mathrm{K}^{-2}$ was achieved by PCu(epy)-SWCNT at $f_{\mathrm{C}}=75 \%$. In summary, the TE properties of the PM(epy)-SWCNT composites at $f_{C}=75 \%$ are summarized in Table 2 .

Table 2. The TE properties of the PM(epy)-SWCNT composites at $f_{C}=75 \%$.

\begin{tabular}{cccc}
\hline Composites & $\sigma\left(\mathbf{S} \cdot \mathbf{m}^{-\mathbf{1}}\right)$ & $S\left(\mu \mathbf{V} \cdot \mathbf{K}^{-\mathbf{1}}\right)$ & $\boldsymbol{P F}\left(\mu \mathbf{W} \cdot \mathbf{m}^{-\mathbf{1}} \cdot \mathbf{K}^{-\mathbf{2}}\right)$ \\
\hline PCo(epy)-SWCNT & $1.13 \times 10^{4}$ & 33.6 & 12.8 \\
PNi(epy)-SWCNT & $1.33 \times 10^{4}$ & 32.5 & 14.1 \\
PCu(epy)-SWCNT & $4.41 \times 10^{4}$ & 29.5 & 38.3 \\
\hline
\end{tabular}




\subsection{Energy Band Analysis}

The solid state UV-Vis diffused reflection spectra (Figure 8a) of neat PM(epy) were acquired to further investigate the factors that affect the electrical conductivity from the perspective of band structure. For the convenience of analysis, the reflection spectra were transformed into the Kubelka-Monk function-photon energy plot (Figure 8b). The optical energy gaps of PCo(epy), PNi(epy), and PCu(epu) were measured to be $2.20 \mathrm{eV}, 2.53 \mathrm{eV}$, and $2.16 \mathrm{eV}$, respectively, suggesting that $\mathbf{P C u}($ epy) possessed the narrowest optical band

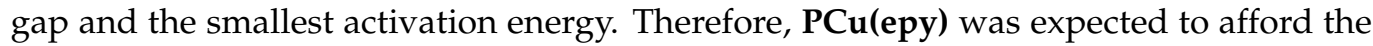
highest electrical conductivity. Besides, as the HOMO level of SWCNT was positioned at $-5.05 \mathrm{eV}[55,56], \mathbf{P C u}($ epy) also gave the narrowest energy gap between the SOMO level of the metallopolymer and the HOMO level of the SWCNT, which was in favour of the hole transport [55] and thus rendered PCu(epy)-SWCNT the most conductive composites in the metallopolymer-SWCNT blending system at almost all doping ratios. As for the PNi(epy)SWCNT composites, although the redox-matching effect was present, the obvious phase separation morphology of the composite films and the wide optical energy gap of PNi(epy) together diminished the electrical conductivity.
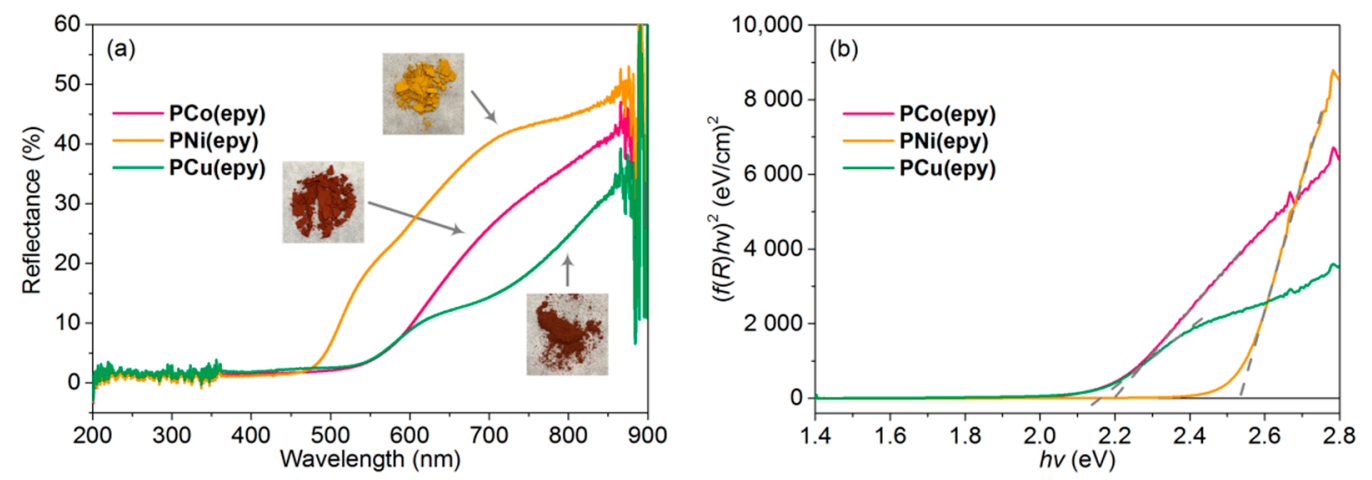

Figure 8. (a) UV-Vis diffused reflection spectra of neat PM(epy) powders. Inset: the photos of each sample taken under daylight. (b) The Kubelka-Monk function versus energy plots of the metallopolymers.

\section{Conclusions}

In summary, three terpyridine-based metallopolymers were synthesized and blended with SWCNT to assess the TE performances of the resulting composite films. CV curves of the neat metallopolymers indicated that the organic backbone was oxidized at ca. $0.45 \mathrm{~V}$ and PNi(epy) displayed an additional oxidation wave corresponding to the conversion from $\mathrm{Ni}(\mathrm{II})$ to $\mathrm{Ni}(\mathrm{III})$ at $0.97 \mathrm{~V}$. Morphology studies showed uniform thin films were gradually formed with an elevated content of SWCNTs, which promoted high electrical conductivities. Raman spectra revealed the presence of the interfacial interactions between the metallopolymers and SWCNTs. TE tests indicated that the electrical conductivity was remarkably enhanced when more SWCNTs were introduced. Particularly, PCu(epy)-SWCNT composites always possessed the highest values compared with other two analogues (i.e., PCo(epy)-SWCNT and PNi(epy)-SWCNT), which was benefited from the well dispersed morphology and the optimized band structures. Among all the prepared composite thin films, the highest $P F$ was achieved by the PCu(epy)-SWCNT composite at $f_{\mathrm{C}}=75 \%$, reaching a value of $38.3 \mu \mathrm{W} \cdot \mathrm{m}^{-1} \cdot \mathrm{K}^{-2}$. This research revealed a promising application prospect of terpyridine-based metallopolymer materials towards TEs, and the metallation process was demonstrated to be a critical but convenient approach to tune the TE properties of these materials. 
Supplementary Materials: The following are available online, Figure S1: Detailed experimental procedures; Figure S2: XPS of the metallopolymers; Figure S3: NMR spectra and mass spectra of the intermediates; Figures S4-S7: UV-Vis-NIR absorption spectrum of the SWCNT dispersion; Figure S8: TEM image of the SWCNT bundles.

Author Contributions: Conceptualization, J.L. and W.-Y.W.; methodology, J.L. and W.-Y.W.; validation, J.L. and W.-Y.W.; formal analysis, J.L., Z.G. and L.X.; investigation, J.L.; resources, J.L. and Z.G.; data curation, J.L.; writing—original draft preparation, J.L.; writing—review and editing, J.L. and W.-Y.W.; supervision, W.-Y.W.; project administration, W.-Y.W.; funding acquisition, W.-Y.W. All authors have read and agreed to the published version of the manuscript.

Funding: This research was funded by the Science, Technology and Innovation Committee of Shenzhen Municipality, grant number JCYJ20180507183413211; the National Natural Science Foundation of China, grant numbers 51873176 and 21905241; Hong Kong Research Grants Council, grant number PolyU123384/16P; the Hong Kong Polytechnic University, grant number 1-ZE1C; Clarea Au Endowed Professorship in Energy, grant number 847S; Research Institute for Smart Energy, grant number CDA2.

Institutional Review Board Statement: Not applicable.

Informed Consent Statement: Not applicable.

Data Availability Statement: Data are contained within the article or the Supplementary Materials.

Conflicts of Interest: The authors declare no conflict of interest.

Sample Availability: Samples of the compounds 1, 2 (see Figure S1 in Supporting Materials), epy, and PM(epy) are available from the authors.

\section{References}

1. Wang, H.; Yu, C. Organic Thermoelectrics: Materials Preparation, Performance Optimization, and Device Integration. Joule 2019, 3, 53-80. [CrossRef]

2. Beretta, D.; Neophytou, N.; Hodges, J.M.; Kanatzidis, M.G.; Narducci, D.; Martin-Gonzalez, M.; Beekman, M.; Balke, B.; Cerretti, G.; Tremel, W.; et al. Thermoelectrics: From History, a Window to the Future. Mater. Sci. Eng. R. 2019, 138, 100501. [CrossRef]

3. Snyder, G.J.; Toberer, E.S. Complex Thermoelectric Materials. Nat. Mater. 2008, 7, 105-114. [CrossRef] [PubMed]

4. Poudel, B.; Hao, Q.; Ma, Y.; Lan, Y.; Minnich, A.; Yu, B.; Yan, X.; Wang, D.; Muto, A.; Vashaee, D.; et al. High-Thermoelectric Performance of Nanostructured Bismuth Antimony Telluride Bulk Alloys. Science 2008, 320, 634-638. [CrossRef] [PubMed]

5. LaLonde, A.D.; Pei, Y.; Snyder, G.J. Reevaluation of $\mathrm{PbTe}_{1-x} \mathrm{I}_{x}$ as High Performance n-Type Thermoelectric Material. Energy Environ. Sci. 2011, 4, 2090-2096. [CrossRef]

6. Zhu, B.; Liu, X.; Wang, Q.; Qiu, Y.; Shu, Z.; Guo, Z.; Tong, Y.; Cui, J.; Gu, M.; He, J. Realizing Record High Performance in n-Type $\mathrm{Bi}_{2} \mathrm{Te}_{3}$-Based Thermoelectric Materials. Energy Environ. Sci. 2020, 13, 2106-2114. [CrossRef]

7. Zhang, Q.; Sun, Y.; Xu, W.; Zhu, D. Organic Thermoelectric Materials: Emerging Green Energy Materials Converting Heat to Electricity Directly and Efficiently. Adv. Mater. 2014, 26, 6829-6851. [CrossRef]

8. Chen, G.; Xu, W.; Zhu, D. Recent Advances in Organic Polymer Thermoelectric Composites. J. Mater. Chem. C 2017, 5, 4350-4360. [CrossRef]

9. Sun, Z.; Li, J.; Wong, W.Y. Emerging Organic Thermoelectric Applications from Conducting Metallopolymers. Macromol. Chem. Phys. 2020, 221, 2000115. [CrossRef]

10. Yao, W.; Shen, L.; Liu, P.; Liu, C.; Xu, J.; Jiang, Q.; Liu, G.; Nie, G.; Jiang, F. Electrochemical Doping Engineering Tuning of the Thermoelectric Performance of a $\pi$-Conjugated Free-Standing Poly(thiophene-furan) Thin-Film. Mater. Chem. Front. 2020, 4 , 597-604. [CrossRef]

11. Fan, Z.; Ouyang, J. Thermoelectric Properties of PEDOT:PSS. Adv. Electron. Mater. 2019, 5, 1800769. [CrossRef]

12. Feng, K.; Xu, L.; Xiong, Y.; Sun, L.; Yu, H.; Wu, M.; Thant, A.A.; Hu, B. PEDOT:PSS and Ni-Based Thermoelectric Generator for Solar Thermal Energy Conversion. J. Mater. Chem. C 2020, 8, 3914-3922. [CrossRef]

13. Liang, L.; Chen, G.; Guo, C.-Y. Polypyrrole Nanostructures and Their Thermoelectric Performance. Mater. Chem. Front. 2017, 1, 380-386. [CrossRef]

14. Fan, W.; Zhang, Y.; Guo, C.-Y.; Chen, G. Toward High Thermoelectric Performance for Polypyrrole Composites by Dynamic 3-Phase Interfacial Electropolymerization and Chemical Doping of Carbon Nanotubes. Composite Sci. Technol. 2019, 183, 107794. [CrossRef]

15. Xiang, M.; Yang, Z.; Chen, J.; Zhou, S.; Wei, W.; Dong, S. Polymeric Thermoelectric Composites by Polypyrrole and Cheap Reduced Graphene Oxide in Towel-Gourd Sponge Fibers. ACS Omega 2020, 5, 29955-29962. [CrossRef]

16. Liang, L.; Gao, C.; Chen, G.; Guo, C.-Y. Large-Area, Stretchable, Super Flexible and Mechanically Stable Thermoelectric Films of Polymer/Carbon Nanotube Composites. J. Mater. Chem. C 2016, 4, 526-532. [CrossRef] 
17. Zhang, J.; Song, G.; Qiu, L.; Feng, Y.; Chen, J.; Yan, J.; Liu, L.; Huang, X.; Cui, Y.; Sun, Y.; et al. Highly Conducting Polythiophene Thin Films with Less Ordered Microstructure Displaying Excellent Thermoelectric Performance. Macromol. Rapid Commun. 2018, 39, 1800283. [CrossRef]

18. Hao, L.; Kang, J.; Shi, J.; Xu, J.; Cao, J.; Wang, L.; Liu, Y.; Pan, C. Enhanced Thermoelectric Performance of Poly(3-Substituted Thiophene)/Single-Walled Carbon Nanotube Composites via Polar Side Chain Modification. Compos. Sci. Technol. 2020, 199, 108359. [CrossRef]

19. Holliday, B.J.; Swager, T.M. Conducting Metallopolymers: The Roles of Molecular Architecture and Redox Matching. Chem. Commun. 2005, 23-36. [CrossRef]

20. Nguyen, M.T.; Jones, R.A.; Holliday, B.J. Understanding the Effect of Metal Centers on Charge Transport and Delocalization in Conducting Metallopolymers. Macromolecules 2017, 50, 872-883. [CrossRef]

21. Nguyen, M.T.; Holliday, B.J. Direct Insights into Metal-Induced Conductivity Enhancement in Conducting Metallopolymers Chem. Commun. 2015, 51, 8610-8613. [CrossRef] [PubMed]

22. Yong, X.; Shi, W.; Wu, G.; Goh, S.S.; Bai, S.; Xu, J.-W.; Wang, J.-S.; Yang, S.-W. Tuning the Thermoelectric Performance of $\pi-\mathrm{d}$ Conjugated Nickel Coordination Polymers through Metal-Ligand Frontier Molecular Orbital Alignment. J. Mater. Chem. A 2018, 6, 19757-19766. [CrossRef]

23. Sun, Y.; Sheng, P.; Di, C.; Jiao, F.; Xu, W.; Qiu, D.; Zhu, D. Organic Thermoelectric Materials and Devices Based on p- and n-Type Poly(Metal 1,1,2,2-Ethenetetrathiolate)s. Adv. Mater. 2012, 24, 932-937. [CrossRef] [PubMed]

24. Jiao, F.; Di, C.A.; Sun, Y.; Sheng, P.; Xu, W.; Zhu, D. Inkjet-Printed Flexible Organic Thin-Film Thermoelectric Devices Based on pand n-Type Poly(Metal 1,1,2,2-Ethenetetrathiolate)s/Polymer Composites through Ball-Milling. Philos. Trans. A Math Phys. Eng. Sci. 2014, 372, 20130008. [CrossRef]

25. Cui, Y.; Yan, J.; Sun, Y.; Zou, Y.; Sun, Y.; Xu, W.; Zhu, D. Thermoelectric Properties of Metal-(Z)-1,2-Dihydroselenoethene-1,2-Dithiol Coordination Polymers. Sci. Bull. 2018, 63, 814-816. [CrossRef]

26. Sheberla, D.; Sun, L.; Blood-Forsythe, M.A.; Er, S.; Wade, C.R.; Brozek, C.K.; Aspuru-Guzik, A.; Dincă, M. High Electrical Conductivity in $\mathrm{Ni}_{3}(2,3,6,7,10,11 \text {-Hexaiminotriphenylene) })_{2}$, a Semiconducting Metal-Organic Graphene Analogue. J. Am. Chem. Soc. 2014, 136, 8859-8862. [CrossRef]

27. Sun, L.; Liao, B.; Sheberla, D.; Kraemer, D.; Zhou, J.; Stach, E.A.; Zakharov, D.; Stavila, V.; Talin, A.A.; Ge, Y.; et al. A Microporous and Naturally Nanostructured Thermoelectric Metal-Organic Framework with Ultralow Thermal Conductivity. Joule 2017, 1, 168-177. [CrossRef]

28. Feng, X.; Liu, L.; Honsho, Y.; Saeki, A.; Seki, S.; Irle, S.; Dong, Y.; Nagai, A.; Jiang, D. High-Rate Charge-Carrier Transport in Porphyrin Covalent Organic Frameworks: Switching from Hole to Electron to Ambipolar Conduction. Angew. Chem. Int. Ed. 2012, 51, 2618-2622. [CrossRef]

29. Chumakov, Y.; Aksakal, F.; Dimoglo, A.; Ata, A.; Palomares-Sánchez, S.A. First-Principles Study of Thermoelectric Properties of Covalent Organic Frameworks. J. Electron. Mater. 2016, 45, 3445-3452. [CrossRef]

30. Patel, M.S. Electrical Conductivity of Chelate Polymers. II. J. Macromol. Sci. B 1987, 26, 97-104. [CrossRef]

31. Gao, C.; Chen, G. A New Strategy to Construct Thermoelectric Composites of SWCNTs and Poly-Schiff Bases with 1,4-Diazabuta1,3-diene Structures Acting as Bidentate-Chelating Units. J. Mater. Chem. A 2016, 4, 11299-11306. [CrossRef]

32. Han, F.S.; Higuchi, M.; Kurth, D.G. Metallo-Supramolecular Polymers Based on Functionalized Bis-Terpyridines as Novel Electrochromic Materials. Adv. Mater. 2007, 19, 3928-3931. [CrossRef]

33. Han, F.S.; Higuchi, M.; Kurth, D.G. Metallosupramolecular Polyelectrolytes Self-Assembled from Various Pyridine RingSubstituted Bisterpyridines and Metal Ions: Photophysical, Electrochemical, and Electrochromic Properties. J. Am. Chem. Soc. 2008, 130, 2073-2081. [CrossRef] [PubMed]

34. Vellis, P.D.; Mikroyannidis, J.A.; Lo, C.-N.; Hsu, C.-S. Synthesis of Terpyridine Ligands and Their Complexation with $\mathrm{Zn}^{2+}$ and $\mathrm{Ru}^{2+}$ for Optoelectronic Applications. J. Polym. Sci. Pol. Chem. 2008, 46, 7702-7712. [CrossRef]

35. Zanardi, C.; Zanfrognini, B.; Morandi, S.; Terzi, F.; Pigani, L.; Pasquali, L.; Seeber, R. Synthesis, Spectroscopic and Electrochemical Characterization of Co(II)-Terpyridine Based Metallopolymer. Electrochim. Acta 2018, 260, 314-323. [CrossRef]

36. Bera, M.K.; Chakraborty, C.; Rana, U.; Higuchi, M. Electrochromic Os(II)-Based Metallo-Supramolecular Polymers. Macromol. Rapid Commun. 2018, 39, e1800415. [CrossRef]

37. Liang, Y.; Strohecker, D.; Lynch, V.; Holliday, B.J.; Jones, R.A. A Thiophene-Containing Conductive Metallopolymer Using an Fe(II) Bis(Terpyridine) Core for Electrochromic Materials. ACS Appl. Mater. Interfaces 2016, 8, 34568-34580. [CrossRef]

38. Ozawa, H.; Yamamoto, Y.; Kawaguchi, H.; Shimizu, R.; Arakawa, H. Ruthenium Sensitizers with a Hexylthiophene-Modified Terpyridine Ligand for Dye-Sensitized Solar Cells: Synthesis, Photo- and Electrochemical Properties, and Adsorption Behavior to the $\mathrm{TiO}_{2}$ Surface. ACS Appl. Mater. Interfaces 2015, 7, 3152-3161. [CrossRef]

39. Zheng, M.; Tan, H.; Xie, Z.; Zhang, L.; Jing, X.; Sun, Z. Fast Response and High Sensitivity Europium Metal Organic Framework Fluorescent Probe with Chelating Terpyridine Sites for $\mathrm{Fe}^{3+}$. ACS Appl. Mater. Interfaces 2013, 5, 1078-1083. [CrossRef] [PubMed]

40. Elgrishi, N.; Chambers, M.B.; Fontecave, M. Turning it off! Disfavouring Hydrogen Evolution to Enhance Selectivity for CO Production during Homogeneous $\mathrm{CO}_{2}$ Reduction by Cobalt-Terpyridine Complexes. Chem. Sci. 2015, 6, 2522-2531. [CrossRef] [PubMed]

41. Liu, Z.; Hu, Y.; Li, P.; Wen, J.; He, J.; Gao, X. Enhancement of the Thermoelectric Performance of DPP Based Polymers by Introducing One 3,4-Ethylenedioxythiophene Electron-Rich Building Block. J. Mater. Chem. C 2020, 8, 10859-10867. [CrossRef] 
42. Fulmer, G.R.; Miller, A.J.M.; Sherden, N.H.; Gottlieb, H.E.; Nudelman, A.; Stoltz, B.M.; Bercaw, J.E.; Goldberg, K.I. NMR Chemical Shifts of Trace Impurities: Common Laboratory Solvents, Organics, and Gases in Deuterated Solvents Relevant to the Organometallic Chemist. Organometallics. 2010, 29, 2176-2179. [CrossRef]

43. Larkin, P.J. Chapter 6-IR and Raman Spectra-Structure Correlations: Characteristic Group Frequencies. In Infrared and Raman Spectroscopy, 2nd ed.; Larkin, P.J., Ed.; Elsevier: Amsterdam, The Netherlands, 2018; pp. 85-134.

44. Park, J.G.; Aubrey, M.L.; Oktawiec, J.; Chakarawet, K.; Darago, L.E.; Grandjean, F.; Long, G.J.; Long, J.R. Charge Delocalization and Bulk Electronic Conductivity in the Mixed-Valence Metal-Organic Framework Fe(1,2,3-Triazolate) ${ }_{2}\left(\mathrm{BF}_{4}\right)_{x}$. J. Am. Chem. Soc. 2018, 140, 8526-8534. [CrossRef]

45. Sun, Q.; Wang, H.; Yang, C.; Li, Y. Synthesis and Electroluminescence of Novel Copolymers Containing Crown Ether Spacers. J. Mater. Chem. 2003, 13, 800-806. [CrossRef]

46. Hsu, C.-Y.; Zhang, J.; Moriyama, S.; Higuchi, M. Solvent Effect on Electrochemical Properties of a Co(II)-Based MetalloSupramolecular Polymer Film. Macromol. Symp. 2016, 363, 12-19. [CrossRef]

47. Buriez, O.; Labbé, E.; Périchon, J. Unexpected Stabilization of a Simple Cobalt(I) Salt in Acetonitrile at a Glassy Carbon Electrode. J. Electroanal. Chem. 2006, 593, 99-104. [CrossRef]

48. Chen, D.; Fabre, P.-L.; Reynes, O. Electrocarboxylation of Chloroacetonitrile by a Cobalt(I) Complex of Terpyridine. Electrochim. Acta 2011, 56, 8603-8610. [CrossRef]

49. Nanot, S.; Thompson, N.A.; Kim, J.-H.; Wang, X.; Rice, W.D.; Hároz, E.H.; Ganesan, Y.; Pint, C.L.; Kono, J. Single-Walled Carbon Nanotubes. In Springer Handbook of Nanomaterials; Vajtai, R., Ed.; Springer: Berlin, Germany, 2013; pp. 105-146.

50. Wolf, M.O. Recent Advances in Conjugated Transition Metal-Containing Polymers and Materials. J Inorg. Organomet. Polym. Mater. 2006, 16, 189-199. [CrossRef]

51. Zhou, Y.; Liu, Y.; Zhou, X.; Gao, Y.; Gao, C.; Wang, L. High Performance p-Type Organic Thermoelectric Materials Based on Metalloporphyrin/Single-Walled Carbon Nanotube Composite Films. J. Power Sources 2019, 423, 152-158. [CrossRef]

52. Meng, C.; Liu, C.; Fan, S. A Promising Approach to Enhanced Thermoelectric Properties Using Carbon Nanotube Networks. Adv. Mater. 2010, 22, 535-539. [CrossRef]

53. Gregory, S.A.; Menon, A.K.; Ye, S.; Seferos, D.S.; Reynolds, J.R.; Yee, S.K. Effect of Heteroatom and Doping on the Thermoelectric Properties of Poly(3-alkylchalcogenophenes). Adv. Energy Mater. 2018, 8, 1802419. [CrossRef]

54. Zhou, X.; Pan, C.; Liang, A.; Wang, L.; Wong, W.-Y. Thermoelectric Properties of Composite Films Prepared with Benzodithiophene Derivatives and Carbon Nanotubes. Compos. Sci. Technol. 2017, 145, 40-45. [CrossRef]

55. Zhou, Y.; Yin, X.; Liu, Y.; Zhou, X.; Wan, T.; Wang, S.; Gao, C.; Wang, L. Significantly Enhanced Power Factors of p-Type Carbon Nanotube-Based Composite Films by Tailoring the Peripheral Substituents in Porphyrin. ACS Sustain. Chem. Eng. 2019, 7, 11832-11840. [CrossRef]

56. Kim, T.-h.; Jang, J.G.; Hong, J.-I. Enhanced Thermoelectric Performance of SWNT/Organic Small Molecule (OSM) Hybrid Materials by Tuning of the Energy Level of OSMs. J. Mater. Chem. C 2020, 8, 12795-12799. [CrossRef] 